\title{
Tetralogy of fallot in a two-month-old holstein calf
}

\author{
Sümbül Serap BİRINCİĞLU ${ }^{1}$, Emrah İPEK ${ }^{2}$, Ayşe Nur AKKOÇ², Hamdi AVCI ${ }^{2}$, Ahmet AYDOĞAN³ $^{3}$
}

${ }^{1}$ Special A Pathology Laboratory, İzmir/TURKEY

${ }^{2}$ Department of Pathology, Faculty of Veterinary Medicine, Aydın Adnan Menderes University, Aydın/TURKEY

${ }^{3}$ Department of Pathology, Faculty of Veterinary Medicine, Çukurova University, Adana/TURKEY

Key Words:

calf

holstein

pathology

tetralogy of fallot

Received $\quad: 12.04 .2020$

Accepted : : 18.06 .2020

Published Online : 30.12 .2020

Article Code : 813073

\begin{abstract}
In this case report, a case of tetralogy of fallot ( $\mathrm{ToF}$ ) in a two-month-old female, Holstein breed calf was described. Following necropsy examination, all tissue samples were collected and fixed in $\% 10$ buffer formalin solution, embedded in paraffin, sectioned at $5 \mu \mathrm{m}$ and stained routinely with Hematoxylin-Eosin. At necropsy, the heart was enlarged; the pericardium was edematous, opaque and was distended with fluid transudate. In the heart, pulmonary stenosis with a diameter of $1.8 \mathrm{~cm}$, a defect ( $3 \mathrm{~cm}$ in diameter) in the cranial of the interventricular septum, dilatation of the right ventricle and thickening of its wall and right displacement of the aorta on the interventricular septum were observed. According to these findings, the present case was diagnosed as ToF. To the best of our knowledge, this is the first case of ToF in a calf in Turkey.
\end{abstract}

Correspondence:

A. AYDOGAN

(aaydogan@cu.edu.tr)

ORCID:

SS. BIRINCİOĞLU : 0000-0001-5815-6508

$: 0000-0002-5247-5222$

AN. AKKOC : :0000-0003-4862-013X

H. AVCI :0000-0002-7776-5373

A. AYDOĞAN :0000-0003-2504-8150

*This case report was presented as poster at the 8th National Veterinary Pathology Congress, 01-03. September.2016, Samsun, Turkey

\section{INTRODUCTION}

Congenital heart anomalies of cattle are rarely seen with a prevalence of $0.17 \%$. However, these defects form an important part of all bovine congenital defects. Tetralogy of fallot (ToF), one of these defects, is a complex congenital hearth disease and is reported from dogs, cats, cattle, sheep and wild animals $(1,2,3)$. ToF is characterized by 4 components which are 1) ventricular septal defect (VSD); 2) stenosis or obstruction of the right ventricular outflow track (RVOT stenosis) and pulmonary stenosis (PS); 3) right displacement of the aorta; and 4) hypertrophy of the right ventricle. In ToF, animals experience weakness, rapid fatigue, difficulty breathing, cyanosis and developmental retardation clinically (3-6).

In this case report, we aimed to describe ToF case in a calf macroscopically and microscopically.

\section{CASE HISTORY}

A two-month-old female, Holstein breed calf was brought dead to the pathology laboratory. Systemic necropsy of the calf was performed. Tissue samples taken for histopat- hological examination were fixed in 10\% formalin solution, processed routinely and blocked in paraffin. Five $\mu \mathrm{m}$ thick microtome sections from paraffin blocks were used to stain with Hematoxylin and Eosin (H\&E) technique. Prepared slides were examined under light microscope.

It is reported that weakness, anorexia and dyspnea were seen in the calf clinically. Grossly, cyanosis in mucous membranes, widespread edema in the neck region together with clear yellowish fluid accumulation in the abdominal and thoracic cavities were observed. The mesentery was quite edematous, and the serosal vessels were hyperemic.

Pericardium was edematous and in opaque appearance. The heart was markedly large and round-shaped (Fig. 1). $480 \mathrm{ml}$ of clear yellow liquid was found in the lumen. There were four findings compatible with ToF in the heart which was opened according to the necropsy technique. These are: 1) pulmonary stenosis (arteria pulmonalis) with a diameter of $1.8 \mathrm{~cm}$ (Fig. 2); 2) a defect (3 cm in diameter) in the cranial of the interventricular septum (Fig. 3); 3) dilatation of the right ventricle and thickening of its wall (hypertrophy) (Fig. 4); 4) right displacement of the aorta on the interventricular septum 


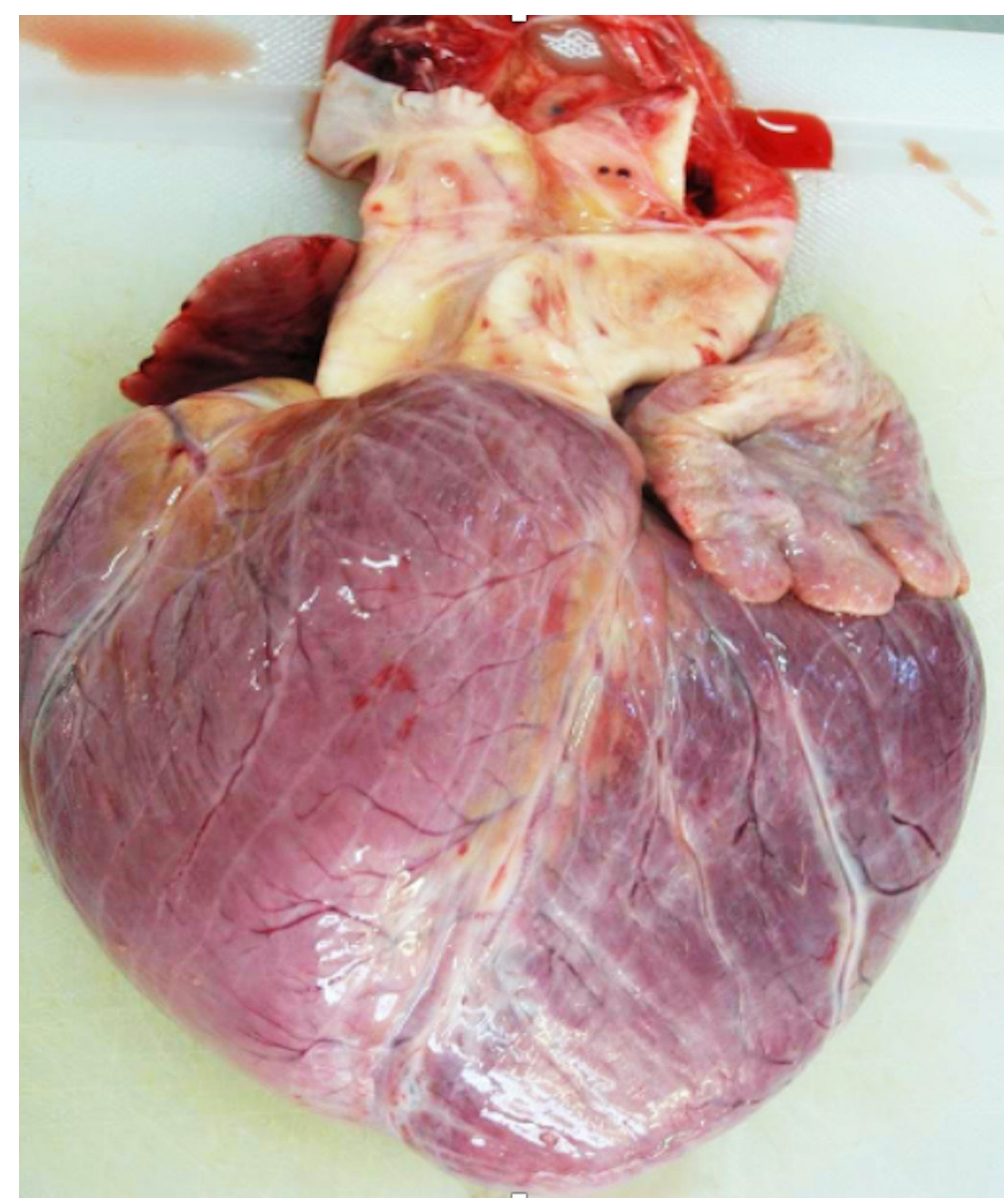

Figure 1. View of the Heart. Enlargement of the heart and rounding of the cardiac apex

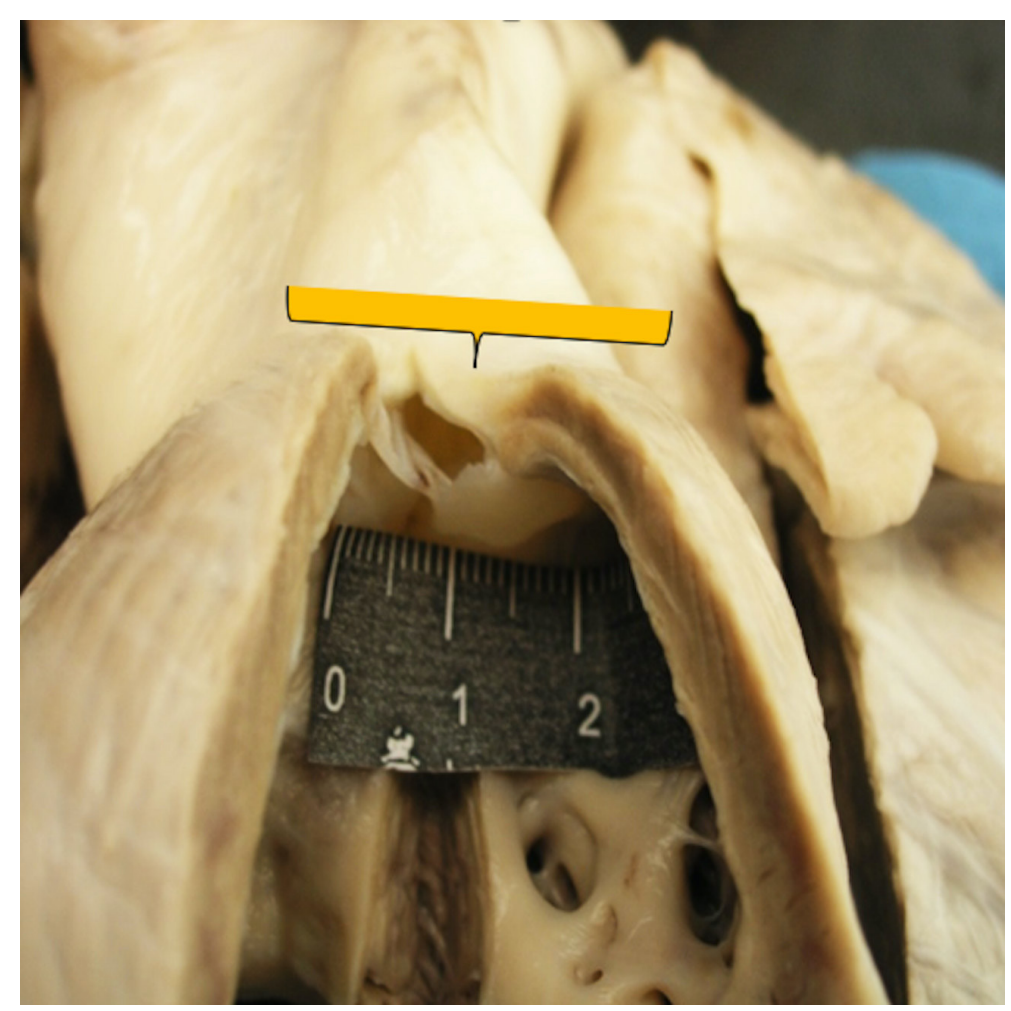

Figure 2. Heart. Stenosis in arteria pulmonalis 


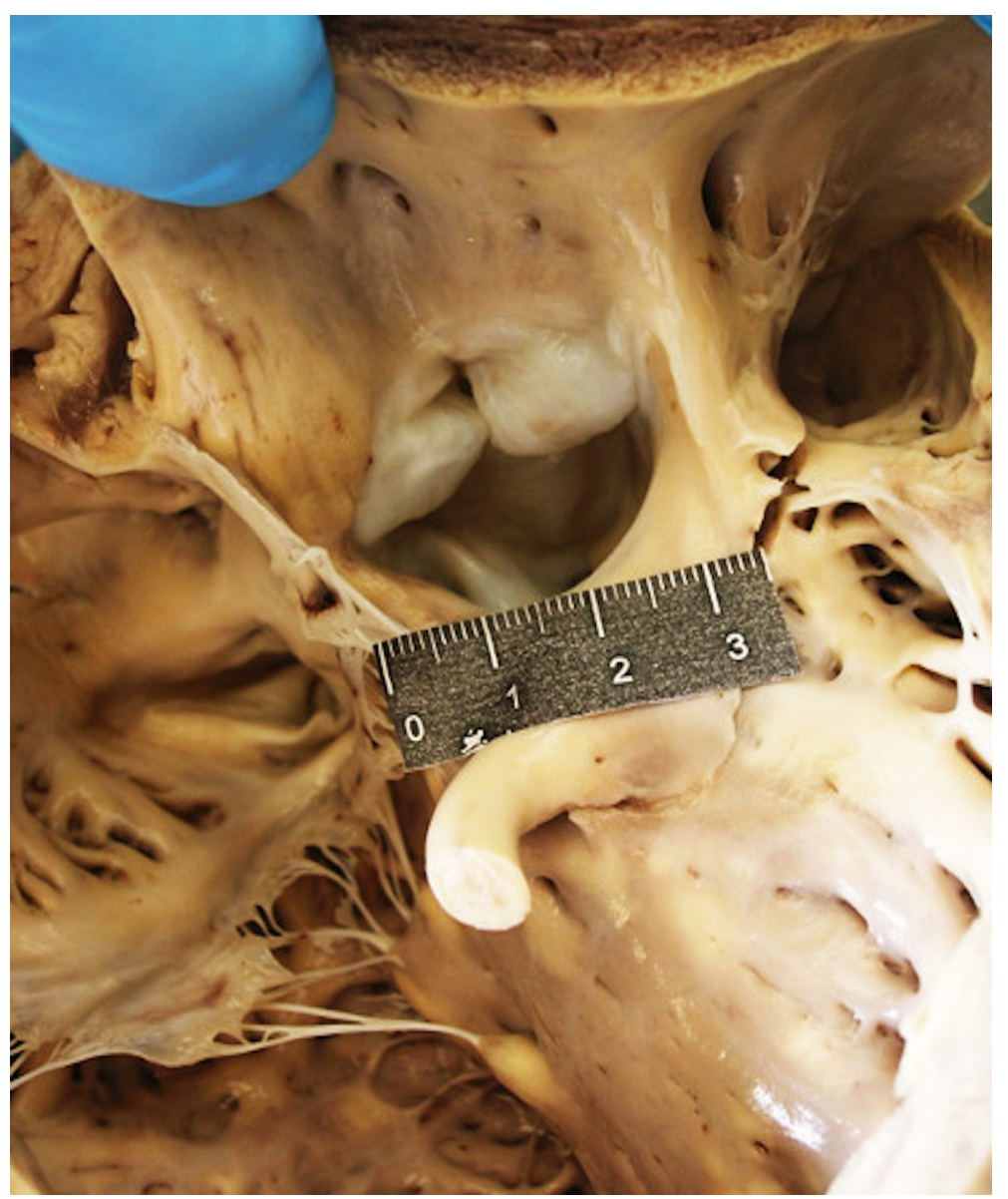

Figure 3. Heart. A defect (3 $\mathrm{cm}$ in diameter) in the cranial of the interventricular septum

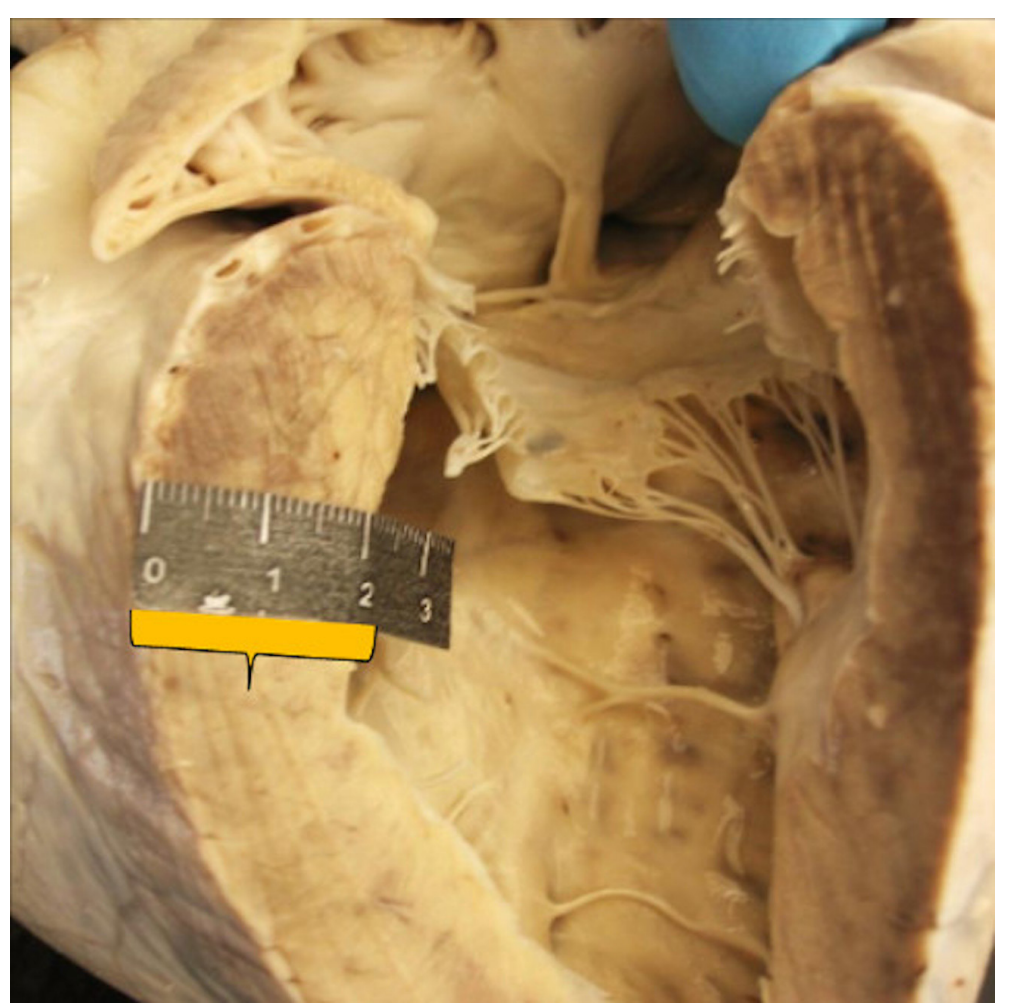

Figure 4. Heart. Dilatation of the right ventricle and thickening of its wall (hypertrophy) 


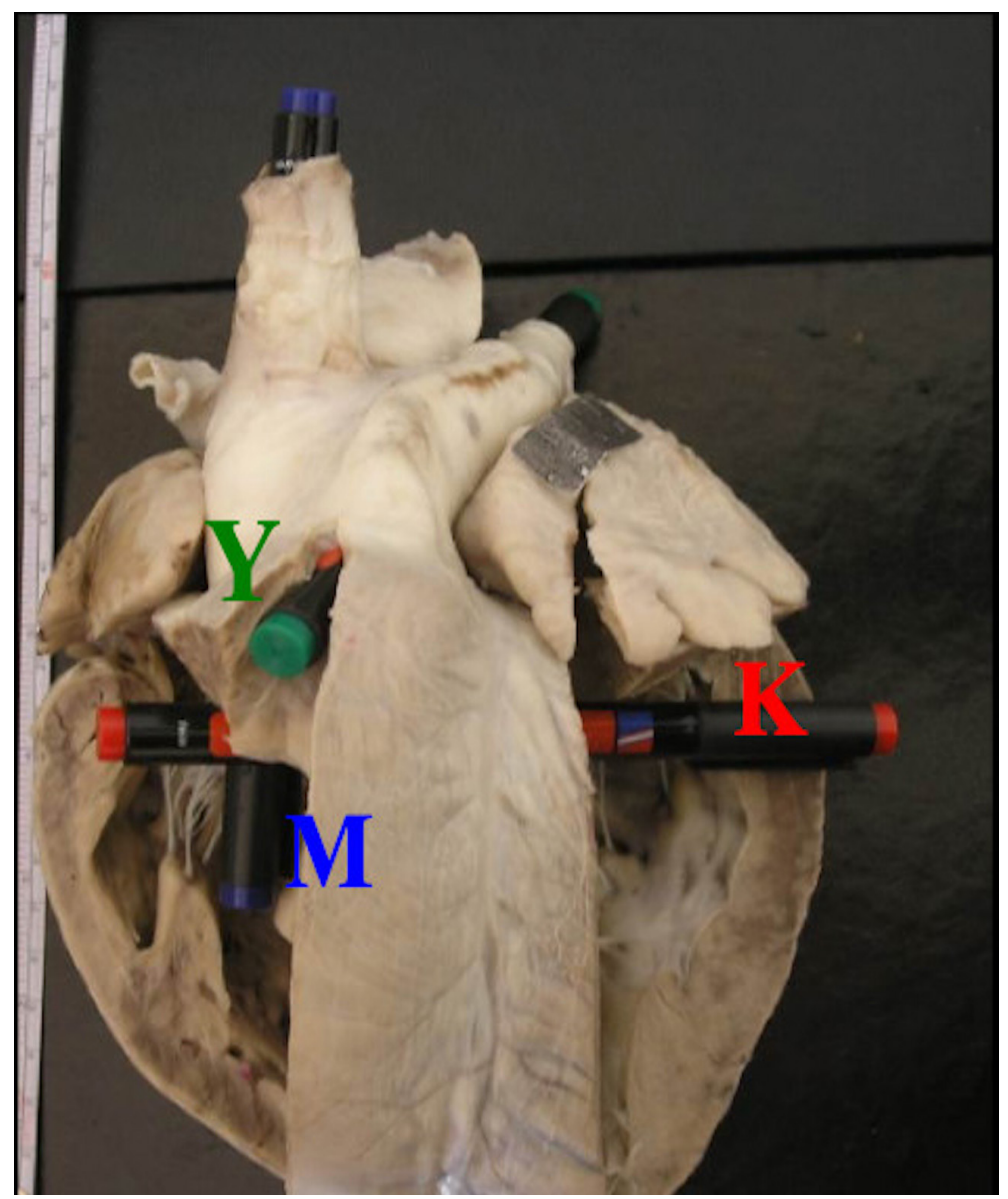

Figure 5. Heart. K: A defect in the cranial of the interventricular septum, $\mathbf{Y}$ : Stenosis in arteria pulmonalis, M: Right displacement of the aorta on the interventricular septum.

(Fig. 5). It was noted that the left and right ventricles were 14.0 x $9.0 \times 7.5 \mathrm{~cm}$ and $14.5 \times 7.0 \times 11.5 \mathrm{~cm}$ in size respectively. In addition, the lungs were edematous and swollen. In the cranial lobes of the lung, dark red patchy consolidated areas were found. A foamy and bloody fluid was oozing out from the cut surfaces of the lungs. The liver was enlarged, pale, hard consistency with blunt edges and the capsule was thickened.

In histopathological examination, the most prominent lesion encountered in myocardium was hypertrophy and vacuolar degeneration of cardiomyocytes. The cytoplasm of degenerate myocytes was swollen, pale and vacuolar. Widespread edema and neutrophil leukocyte infiltrations were observed in alveoli of the lungs. Chronic congestion, diffuse dystrophy in hepatocytes of the peri acinar region and diffuse fibrosis around the vena centralis and Glisson's triangle were determined in the liver.

\section{DISCUSSION}

ToF is a rare congenital heart anomaly in animals and more common in humans. In animals, it is most often described in dogs, spontaneously in other animal species (6). In this report, a case of ToF encountered spontaneously in a calf is described pathologically.

In humans, on a genetic basis, some genes have been revealed in etiology of ToF, including Jagged-1, NKX2-5, and ZFPM2 (zinc finger protein multitype 2) (7-9). However, gene- tic tests were not performed in this case.

Radiological and ultrasonagraphic examinations, contrast angiocardiography, and echocardiography (ECG) are the methods used in the diagnosis of this anomaly (5-6). In this case, however, none of these diagnosis methods were performed during the antemortem period. In this calf brought dead to pathology laboratory, only pathological examinations were performed and anamnesis information with heart lesions were evaluated together. Similarly, in a case report of ToF, the diagnosis is confirmed as tetralogy of fallot on pathological examination (5). In accordance with the literature, 4 components of ToF were determined in necropsy of present case as pulmonary stenosis, a defect in the cranial interventricular septum, dilatation and hypertrophy of the right ventricle, and right displacement of the aorta on the interventricular septum (3-6). In the light of these findings, ToF was diagnosed. In ToF cases, cyanosis in mucous membranes can occur as a sequel to shunting of blood between the two ventricles (5). In this case, cyanosis was thought to occur due to shunting of blood between the two ventricles.

The pathology of ToF related lesions in other parts of the body depends on systemic vascular resistance and heart failure (5-6). In the present case, systemic edema, determined pathological findings of the lungs and liver of the animal were evaluated as a natural consequence of heart failure and systemic vascular resistance. 
In conclusion, we present a unique case of ToF in a Holstein calf. To the best of our knowledge, this case represents the first case of ToF in Turkey. In this context, this report may help veterinary clinicians get at the most likely diagnosis in Turkey.

\section{CONFLICT of INTEREST}

The authors declare no conflicts of interest with respect to the publication of this manuscript.

\section{REFERENCES}

1. Agren E, Soderberg A, Morner T. Fallot's tetralogy in a European brown bear (Ursus arctos). J. Wildl. Dis. 2005; 41: $825-828$.

2. Neill CA, Clark BE. Tetralogy of Fallot: The first 300 years. Texas Heart Inst. J. 1994; 21: 272-279.

3. Michaelson M, Ho SY. Congenital Heart Malformations in Mammals: An Illustrated Text. London; Imperial College Press; 2000.

4. Fruganti A, Cerquetella M, Beribe F, Spaterna A, Tesei B. Clinic and ultrasonographic findings in a cat with Tetralogy of Fallot. Vet. Res.Commun. 2004; 28: 343-346.

5. Mohamed T, Sato H, Kurosawa T, Oikawa S, Nakade T, Koiwa M. Tetralogy of Fallot in a calf: clinical, ultrasonographic, laboratory and postmortem findings. J. Vet. Med. Sci. 2004; 66: 73-76.

6. Paslawska U, Nowak AN, Cepiel A, Staszczyk M, Janiszewski A. A retrospective study of tetralogy of Fallot in dogs. Turk. J. Vet. Anim. Sci. 2013; 37: 57-60.

7. Eldadah ZA, Hamosh A, Biery NJ, Montgomery RA, Duke M, Elkins R, Dietz HC. Familial tetralogy of Fallot caused by mutation in the jagged1 gene. Hum. Molec. Genet. 2001; 10: 163-169.

8. Goldmuntz E, Geiger E, Benson DW. NKX2.5 mutations in patients with tetralogy of Fallot. Circulation. 2001; 104: 2565-2568.

9. Pizutti A, Sarkozy A, Newton AL, Conti E, Flex E, Digilio MC, Amani F, Gianni D, Tandoi C, Marino B, Crossley M, Dallapiccola B. Mutations of ZFPM2/FOG2 gene in sporadic cases of tetralogy of Fallot. Hum. Mutat. 2003; 22: 372-377. 